\title{
Decoupling the effects of logging and hunting on an Afrotropical animal community
}

\author{
J. R. Poulsen, ${ }^{1}$ C. J. Clark, ${ }^{1}$ And B. M. Bolker ${ }^{2}$ \\ Department of Biology, P.O. Box 11852, University of Florida, Gainesville, Florida 32611-8525 USA
}

\begin{abstract}
In tropical forests, hunting nearly always accompanies logging. The entangled nature of these disturbances complicates our ability to resolve applied questions, such as whether secondary and degraded forest can sustain populations of tropical animals. With the expansion of logging in central Africa, conservation depends on knowledge of the individual and combined impacts of logging and hunting on animal populations. Our goals were (1) to decouple the effects of selective logging and hunting on densities of animal guilds, including apes, duikers, monkeys, elephant, pigs, squirrels, and large frugivorous and insectivorous birds and (2) to compare the relative importance of these disturbances to the effects of local-scale variation in forest structure and fruit abundance. In northern Republic of Congo, we surveyed animals along 30 transects positioned in forest disturbed by logging and hunting, logging alone, and neither logging nor hunting. While sampling transects twice per month for two years, we observed 47179 animals of 19 species and eight guilds in 1154 passages $(2861 \mathrm{~km})$. Species densities varied by as much as $480 \%$ among forest areas perturbed by logging and/or hunting, demonstrating the strong effects of these disturbances on populations of some species. Densities of animal guilds varied more strongly with disturbance type than with variation in forest structure, canopy cover, and fruit abundance. Independently, logging and hunting decreased density of some guilds and increased density of others: densities varied from $44 \%$ lower (pigs) to $90 \%$ higher (insectivorous birds) between logged and unlogged forest and from $61 \%$ lower (apes) to $77 \%$ higher (frugivorous birds) between hunted and unhunted forest. Their combined impacts exacerbated decreases in populations of some guilds (ape, duiker, monkey, and pig), but counteracted one another for others (squirrels, insectivorous and frugivorous birds). Together, logging and hunting shifted the relative abundance of the animal community away from large mammals toward squirrels and birds. Logged forest, even in the absence of hunting, does not maintain similar densities as unlogged forest for most animal guilds. To balance conservation with the need for economic development and wild meat in tropical countries, landscapes should be spatially managed to include protected areas, community hunting zones, and production forest.
\end{abstract}

Key words: animal community; animal density; Congo; guilds; habitat variables; hunting; logging; transects; tropical forest; zero-inflated Poisson.

\section{INTRODUCTION}

Deforestation and forest degradation have transformed most tropical forests from vast expanses of old growth to mosaics of secondary species interspersed with sparse patches of primary forest (Lamb et al. 2005). At debate is whether this mosaic of tropical forest dominated by degraded forest can support the majority of species (Laurance 2007). On one hand, the conversion of forest for agriculture, ranching, and intensive logging

Manuscript received 28 May 2010; revised 2 September 2010; accepted 18 October 2010. Corresponding Editor: T. G. O'Brien.

${ }^{1}$ Present address: Woods Hole Research Center, 149 Woods Hole Road, Falmouth, Massachusetts 02540-1644 USA. E-mail: jpoulsen@whrc.org

2 Present address: Department of Mathematics and Statistics and Department of Biology, 1280 Main Street West, McMaster University, Hamilton, Ontario L8S 4K1 Canada. has already led to local extinctions of animals in some tropical regions (Brook et al. 2003, Curran et al. 2004). This evidence endorses the view that secondary forests are characterized by lower biodiversity than primary forest, support a predominance of generalist species, and act as reproductive sinks (Brook et al. 2006). If habitat loss continues, as predicted by some models (Laurance 2001, Soares et al. 2006), then mass extinctions of tropical species are anticipated (Dirzo and Raven 2003, Sodhi et al. 2004). On the other hand, current human demographic trends provide reason to think that deforestation will slow, allowing forests to regrow and animal species to recover (Wright and Muller-Landau 2006a). Secondary and degraded forest might rescue threatened species unlikely to persist in remnants of primary forest (Wright and Muller-Landau 2006b). After all, not all secondary forest is depauperate, and some studies have shown that logged and unlogged forests can support similar plant species diversity 
(Cannon et al. 1998) and animal abundance (Clark et al. 2009).

The debate over whether secondary forest can maintain populations of tropical animals is particularly relevant for the forests of central Africa where logging is one of the principal drivers of tropical forest degradation. The last decade has seen a dramatic expansion in road construction for logging, opening the remaining interior forests to timber operations (Laporte et al. 2007). Though central Africa still retains nearly $60 \%$ of its original forest (Naughton-Treves and Weber 2001), logging concessions now occupy $30-45 \%$ of remaining forests, reaching $70 \%$ of forests in some countries (Global Forest Watch 2002, Laporte et al. 2007). If logged forest can support a similar diversity and abundance of tropical animals as unlogged forest, then 60 million hectares of Afrotropical forest could be potentially managed for animal populations, a major gain for biodiversity conservation and a possible source of wild meat for the rural poor.

To resolve the debate over the conservation value of degraded forest, we need a better understanding of the factors that limit the ability of animal species and communities to persist in the face of disturbance. Alarmingly, we seem to lack the field data necessary to translate the consequences of forest degradation into conservation and management policy (Gardner et al. 2007). One explanation for the insufficiency of data is that multiple types of disturbances operate simultaneously. For example, industrial logging in central Africa is nearly always accompanied by hunting: hunters use logging roads to gain entry into frontier forests and to transport wild game back to markets (Robinson et al. 1999, Wilkie et al. 2000). But logging and hunting likely have very different impacts on tropical animal populations. Commercial logging modifies landscape-scale forest structure, local environmental variables, and resource abundance (reviewed in Putz et al. 2001). This alteration of the forest might be beneficial to some species and detrimental to others, depending on their habitat and resource needs and demographic characteristics. Hunting reduces animal abundance and leads to local extinctions where it is intense, but not all species are equally targeted (Jerozolimski and Peres 2003). Reductions in the abundance of targeted species could provide ecological release for nontargeted species. Thus, the different impacts of logging and hunting may be difficult to predict and they may have opposing effects or reinforce one another.

The challenge then is to decouple logging and hunting so that their individual and combined impacts on animal populations can be understood. With this information, management of degraded forests can actively address the threats most deleterious to tropical animals. We established a large-scale study to decouple the effects of logging and hunting in lowland tropical forest in the Republic of Congo (Brazzaville). In forest disturbed by logging and hunting, logging alone, and neither logging nor hunting, we surveyed a broad range of animal species over two years to quantify densities of animal species and guilds. Specifically, we sought to (1) compare species and guild densities among these forest areas as an estimate of the impact of logging, hunting, and the combination of logging and hunting on tropical animals and (2) compare the relative importance of logging and hunting on guild densities to other variables, including geographical position, forest structure, light availability, and fruit abundance, that might also determine abundances of tropical species. Species of the greatest conservation concern are often rare, with field surveys frequently resulting in an abundance of zero values. We therefore employ zero-inflated models that appropriately model the source of zero observations to examine the impact of disturbance on several guilds of forest animals, including endangered apes and elephants. While this study offers insights into the importance of separating the effects of disturbance from one another and examining their differential effects on multiple species and guilds, our results represent the environmental and human context of a single study site in northern Congo and should only be extrapolated to other sites with care.

\section{Methods \\ Study area and design}

We conducted the study in the Nouabale-Ndoki National Park (NNNP; 400000 ha) and the Kabo logging concession (KLC; 267000 ha) in northern Republic of Congo (study site described in Clark et al. 2009, Poulsen et al. 2009; Fig. 1). The NNNP has never been logged and is protected from hunting. The KLC borders the NNNP to the south, and together they include a contiguous mosaic of logged and unlogged forest. Between 25 and 30 years before the study, this area of the KLC was selectively logged at low intensity $(<2.5$ trees/ha) with four species, Entandophragma cylindricum, E. utile, Triplochiton scleroxylon, and Milicia excelsa, comprising $90 \%$ of the cutting volume (Congolaise Industrielle des Bois 2006). Approximately 3000 people inhabit the study area, most of whom live in the logging town of Kabo. Residents hunt with shotguns, and to a lesser extent with wire snares, to supplement their diets and for commercial trade in the logging town. Duikers, monkeys, and forest pigs made up $85.5 \%$ of all hunted species in markets in logging towns, whereas birds and rodents each made up $0.1 \%$ and $3.2 \%$ of bushmeat (Poulsen et al. 2009). A corps of eco-guards in the KLC and NNNP strictly enforces a hunting ban on protected species such as apes and elephants and a company-imposed ban on the transport of hunters, weapons, and bushmeat on logging vehicles (Elkan et al. 2006, Poulsen et al. 2007). Poaching of elephants for the ivory trade does occur in KLC, but it is relatively rare (on the order of 10 elephants per year). Law enforcement has likely contributed to the conservation of protected species as densities of apes and 


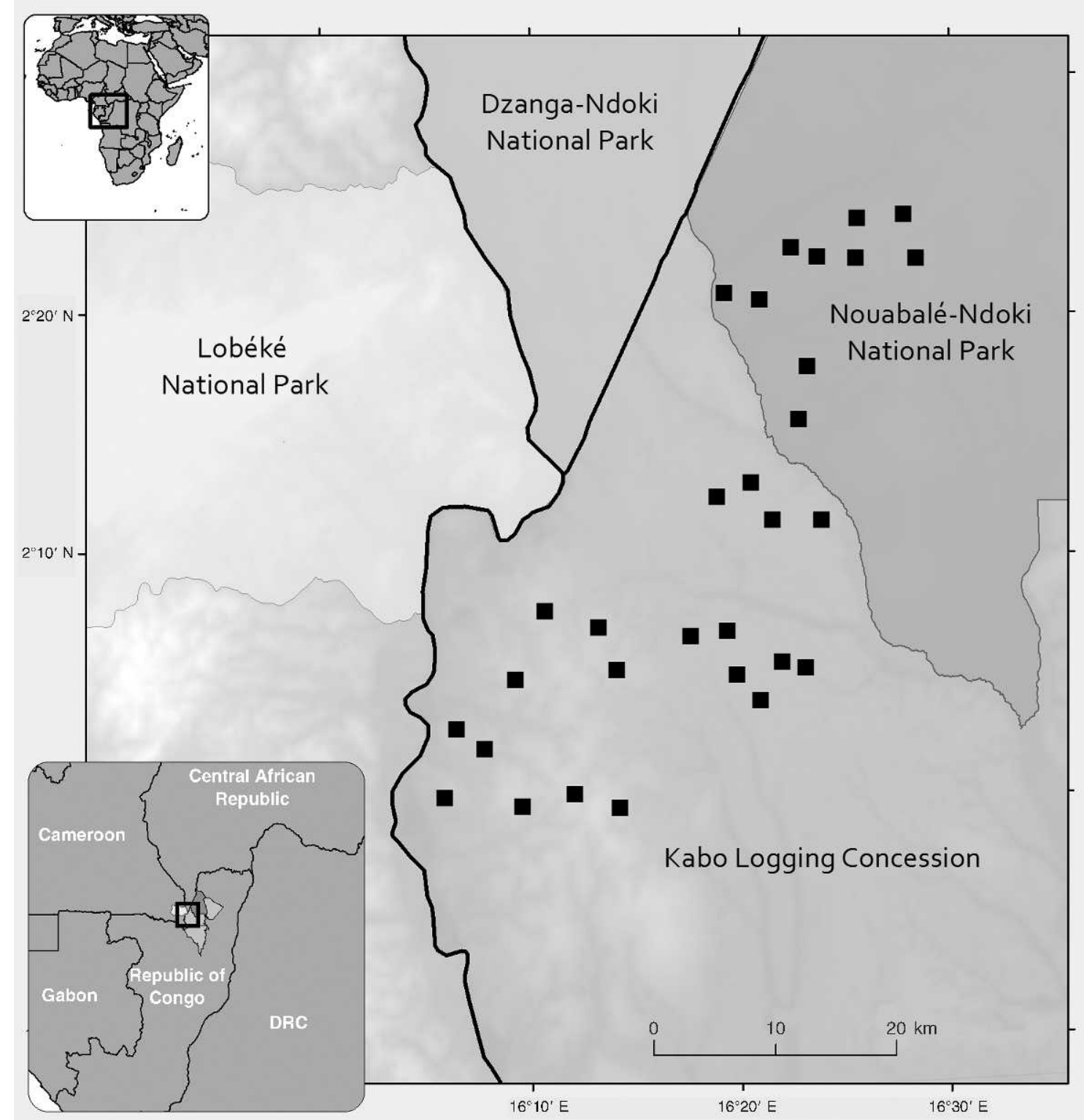

FIG. 1. Map of study area in northern Republic of Congo, Africa. The inset maps show the area within Africa (upper left panel) and within the region (lower left panel). The study area is located in a larger landscape including multiple concessions and protected areas, including the Lobéké National Park in Cameroon, the Ndoki National Park in the Central African Republic, and the Nouabale-Ndoki National Park in the Republic of Congo. Thirty sites, indicated by the squares, were positioned in a random stratified manner in the Kabo concession and the Nouabalé-Ndoki National Park (NNNP). Each site includes a 2500-m transect linked to a 1-ha tree plot, and all sites are separated by at least $2.5 \mathrm{~km}$.

elephant in the area are higher in managed forest than forest not managed for wildlife (Stokes et al. 2010). Most hunting originates from the town of Kabo, resulting in a gradient of hunting intensity that decreases with distance from the town with some variation with vegetation type (Mockrin 2008). Congolese hunting laws specify a hunting season from May to October, set quotas for off-take, and protect endangered species. The forests are classified as lowland tropical forest, and dominant tree families include Meliaceae, Euphor- biaceae, and Annonaceae. Meteorological data collected daily at the Bomassa Research Station, which lies near the center of the study sites, indicate that annual rainfall averaged $1518 \mathrm{~mm}(\mathrm{SD}=96)$ from 2001 to 2006 and is seasonal with peaks in May and October.

Within the NNNP and KLC, we established 30 sites over an area of $\sim 3000 \mathrm{~km}^{2}$. A site was composed of a single $2.5-\mathrm{km}$ transect for quantifying animal densities linked with a 1-ha tree plot for measuring forest diversity and structure and fruit abundance. We 

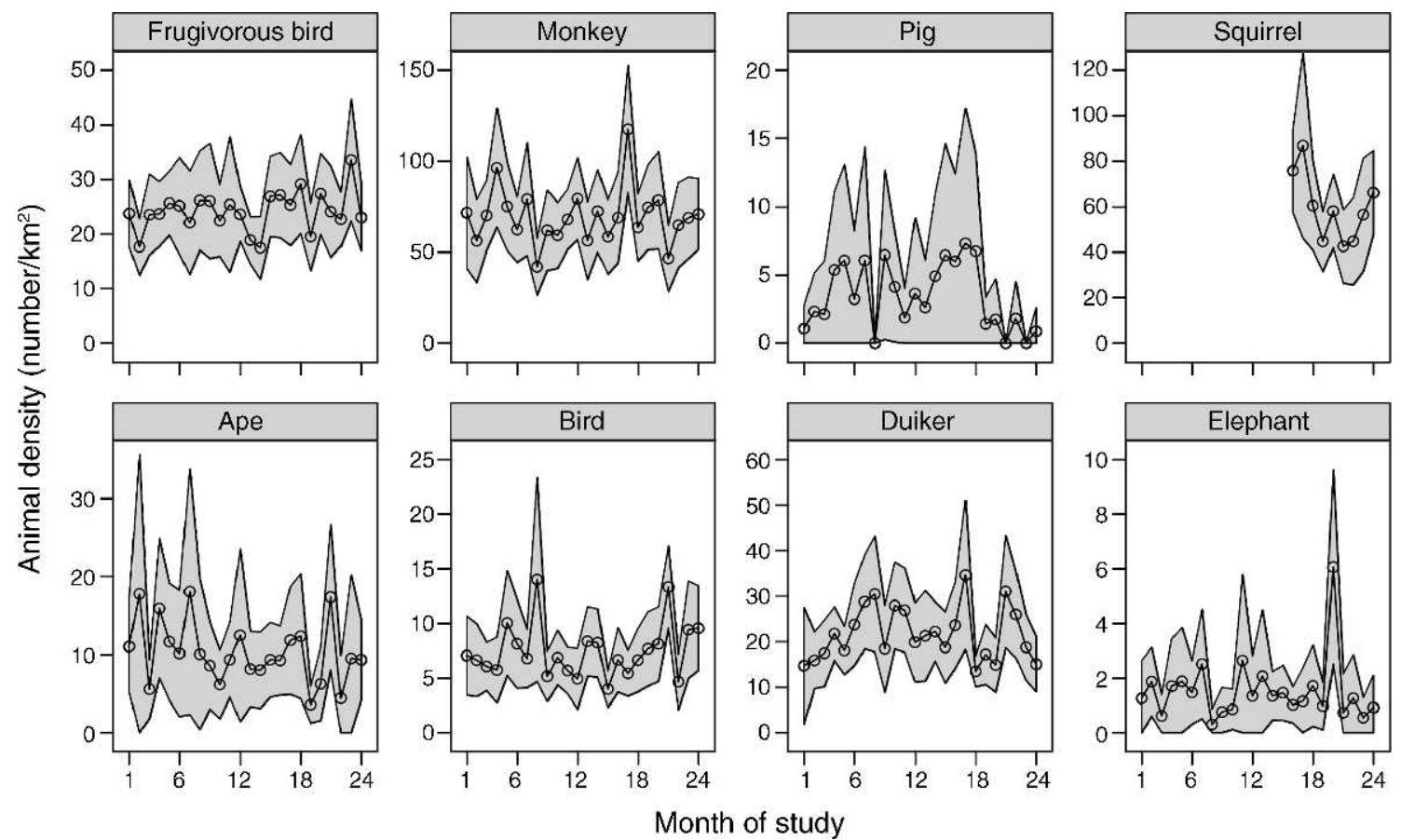

FIG. 2. Densities of animal guilds averaged over all transects during the 24 months from June 2005 to May 2007 (month 1 is June). Shading represents the $95 \%$ confidence intervals around the monthly mean densities. Note that we only systematically sampled squirrels for the last nine months of the study.

randomly located 10 transects and tree plots within each of three different forest types: logged and hunted forest, logged and unhunted forest, and unlogged and unhunted forest. The fourth possible combination, unlogged and hunted forest, did not exist within the park or timber concession. Throughout the paper "forest type" refers to forest areas differentially affected by logging and hunting. We minimized habitat variation among forest types by positioning our sites only in mixed lowland forest, with a buffer of $500 \mathrm{~m}$ to the nearest primary road and $100 \mathrm{~m}$ to the nearest stream or river. Thus, the conclusions from this study are for mixed lowland forest with these constraints in terms of distance from roads and water. Using ArcView 3.2 and a 14-class habitat map, we extracted the areas that did not meet these criteria and then randomly positioned transects on the remaining surface. The $100 \times 100 \mathrm{~m}$ tree plots were positioned $50 \mathrm{~m}$ to the right or left (randomly selected) of the midpoint $(1250 \mathrm{~m})$ of each transect. Transects were oriented perpendicular to water drainage and were separated by a minimum of $2.5 \mathrm{~km}$. We cut narrow trails along each transect and marked the trails every $20 \mathrm{~m}$ with flagging tape. The width of transects was kept as narrow as possible to avoid increased use by hunters or animals over time. We did not observe increasing trends in animal abundance over time (Fig. 2), nor did we observe higher numbers of hunting sign over time or immediately following the opening of transects. Following site establishment, we left all transects and plots undisturbed for one month before sampling for animals or fruit abundance. We monitored the transects and plots for two years, choosing temporal replication over spatial replication (e.g., expanding the number of transects and plots) because one of our goals was to link animal abundance with seed dispersal data and the financial and logistical costs of setting up additional plots were too high.

We designed this study to compare animal densities across forest impacted by hunting, logging, or both hunting and logging as a way of estimating the effects of these disturbances. The strengths of this design are that we control for much of the environmental variation, something that typically cannot be done with large-scale one-off transect designs (e.g., Clark et al. 2009, Stokes et al. 2010), and that it was conducted over a relatively large scale (a $3000 \mathrm{~km}^{2}$ area in northern Congo). The weakness of this design is that it is pseudoreplicated in the sense that transects impacted by the same disturbance type are geographically grouped together (Hurlbert 1984). This is a direct result of the characteristics of the area, particularly the spatial pattern of hunting and logging around the village of Kabo. Pseudoreplication was a necessary trade-off for working in a natural system at a large spatial scale (e.g., Oksanen 2001), but limits the scope of our conclusions to our study system (Cottenie and De Meester 2003). Thus, we emphasize that care needs to be taken in terms of extrapolating our results to other sites with different environmental and human contexts. 
TABLE 1. Estimates (and 95\% CI) of species densities and coefficients of variation (CV) in three types of forest stands: logged, hunted forest; logged, unhunted forest; and unlogged, unhunted forest.

\begin{tabular}{|c|c|c|c|c|c|}
\hline \multirow[b]{2}{*}{ Species } & \multirow{2}{*}{$\begin{array}{l}\text { No. observations } \\
\text { per forest type }\end{array}$} & \multicolumn{3}{|c|}{ Density (no. individuals $/ \mathrm{km}^{2}$ ) by stand type } & \multirow[b]{2}{*}{$\mathrm{CV}$} \\
\hline & & Logged/hunted & Logged/unhunted & Unlogged/unhunted & \\
\hline \multicolumn{6}{|l|}{ Ape } \\
\hline Gorilla gorilla & $46,79,77$ & $1.7(0.8-3.7)$ & $2.4(1.6-3.6)$ & $3.1(2.0-4.7)$ & $19.7-36.7$ \\
\hline Pan troglodytes & $50,60,104$ & $1.7(0.9-3.2)$ & $1.9(0.7-5.0)$ & $6.2(3.2-12.2)$ & $32.5-49.3$ \\
\hline \multicolumn{6}{|l|}{ Duiker } \\
\hline Cephalophus monticola ${ }^{\mathrm{A}, \mathrm{B}}$ & $101,163,210$ & $4.7(3.2-6.9)$ & $12.3(6.94-21.84)$ & $22.5(16.2-31.2)$ & $16.7-29.6$ \\
\hline Cephalophus spp. & $186,226,256$ & $8.9(5.6-14.3)$ & $10.9(8.3-14.2)$ & $13.2(10.3-17.1)$ & $11.9-22.4$ \\
\hline \multicolumn{6}{|l|}{ Elephant } \\
\hline Loxodonta africana & $48,50,32$ & $1.5(0.8-3.0)$ & $0.9(0.5-1.6)$ & $0.4 \dagger(0.2-0.9)$ & $27.3-34.5$ \\
\hline \multicolumn{6}{|l|}{ Frugivorous bird } \\
\hline Bycanistes albotibialis ${ }^{\mathrm{A}, \mathrm{B}}$ & $288,236,270$ & $55.9(41.1-76.1)$ & $32.4(22.4-46.9)$ & $40.7(26.3-62.9)$ & $15.1-22.5$ \\
\hline Bycanistes fistulator ${ }^{\mathrm{A}, \mathrm{B}}$ & $61,63,90$ & $121.5(84.0-175.8)$ & $67.6(39.8-114.7)$ & $25.8(17.6-37.7)$ & $18.7-27.2$ \\
\hline Ceratogymna atrata $^{\mathrm{A}, \mathrm{B}}$ & $197,172,179$ & $29.7(20.6-42.9)$ & $13.6(10.6-17.5)$ & $19.8(14.9-26.31)$ & $12.5-19.9$ \\
\hline 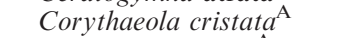 & $198,90,80$ & $26.7(16.3-43.7)$ & $5.4(3.3-9.0)$ & $11.4(5.7-22.8)$ & $23.9-34.9$ \\
\hline Psittacus erithacus ${ }^{\mathrm{A}}$ & $338,280,271$ & $91.9(59.3-142.3)$ & $50.0(33.2-75.4)$ & $31.1(23.1-42.0)$ & $14.8-22.4$ \\
\hline \multicolumn{6}{|l|}{ Bird } \\
\hline Tockus fasciatus $^{\mathrm{B}}$ & $110,89,62$ & $12.0(6.23-23.2)$ & $9.4(5.4-16.4)$ & $1.0(0.6-1.7)$ & $26.3-33.6$ \\
\hline Tockus cameras & $104,126,56$ & $3.8(2.5-5.9)$ & $9.0(6.2-13.1)$ & $2.9(1.8-4.7)$ & $18.8-25.0$ \\
\hline Tockus albocristatus ${ }^{\mathrm{A}, \mathrm{B}}$ & $133,151,134$ & $7.1(3.8-13.5)$ & $17.0(11.4-25.5)$ & $9.8(6.0-16.0)$ & $20.3-32.6$ \\
\hline \multicolumn{6}{|l|}{ Monkey } \\
\hline Cercopithecus nictitans ${ }^{\mathrm{A}, \mathrm{B}}$ & $310,336,361$ & $37.2(24.4-56.8)$ & $41.8(32.8-53.1)$ & $79.7(62.1-102.3)$ & $11.8-19.9$ \\
\hline Cercopithecus pogonias $^{\mathrm{A}, \mathrm{B}}$ & $227,252,259$ & $23.3(15.9-34.2)$ & $28.4(20.5-39.4)$ & $34.9(24.8-49.1)$ & $16.4-19.2$ \\
\hline Cercopithecus cephus ${ }^{\mathrm{A}}$ & $159,184,171$ & $28.3(15.9-50.1)$ & $39.3(17.2-89.3)$ & $39.7(27.8-56.6)$ & $17.8-43.3$ \\
\hline Lophocebus albigena ${ }^{\mathrm{A}, \mathrm{B}}$ & $171,275,318$ & $14.9(6.6-33.5)$ & $26.1(19.8-34.5)$ & $49.5(34.8-70.3)$ & $13.9-42.4$ \\
\hline \multicolumn{6}{|l|}{ Squirrel } \\
\hline Funisciurus lemniscatus ${ }^{\mathrm{A}}$ & $75,80,83$ & $29.4(17.4-49.7)$ & $14.6(10.1-21.1)$ & $12.7(8.4-19.1)$ & $18.4-25.7$ \\
\hline Protoxerus stangeri ${ }^{\mathrm{A}}$ & $56,43,78$ & $26.8(11.9-60.1)$ & $12.6(5.6-28.3)$ & $15.5(9.1-26.5)$ & $26.3-41.9$ \\
\hline
\end{tabular}

Notes: Superscripted letters after the species name indicate a significant difference in density: (A) between logged/hunted forest and logged/unhunted forest; and (B) between logged/unhunted forest and unlogged/unhunted forest. Densities between sites were compared as two-sided $t$ tests and corrected for multiple comparisons so that statistical significance is assessed as $P<0.005$. Other species encountered during the survey with insufficient observations for estimation of densities were: Panthera pardus (carnivore); Cephalophus sylvicultor (duiker); Cercopithecus neglectus, Cercocebus agilis, Piliocolobus badius, and Colobus guereza (monkeys); Hylochoerus meinertzhageni and Potamochoerus porcus (pigs); Atherurus africanus (rodent); and Syncerus caffer nanus and Tragelaphus euryceros (large ungulates).

$\dagger$ Density estimated with fewer than 40 observations.

\section{Animal surveys}

Surveying forest animals is complicated by the difficulty of observing animals in the forest. To obtain sufficient numbers of observations to estimate species densities, most surveys rely on indirect observations of nests for apes and dung for elephant and antelopes. Using indirect observations raises two problems: (1) not all animals leave indices that can be counted, limiting the number of species that can be surveyed, and (2) estimates of animal abundance from indirect observations introduce a great deal of error by assuming constant rates of nest and dung production and decay (Walsh and White 2005). Note, however, that new methods such as retrospective estimation of decay rates can improve the accuracy in the conversion of dung/nest densities to individual animal densities (Laing et al. 2003, Hedges and Lawson 2006). To bypass these difficulties, we surveyed permanent transects that were kept open so that we could make observations of live animals.
Three field teams, each composed of a researcher and a local guide, surveyed the 30 transects twice per month over two years for diurnal mammals and a suite of large bird species (Table 1). Surveys began between 06:00 and 07:00 when animals were the most active. Observers walked slowly $(\sim 1.2 \mathrm{~km} / \mathrm{h})$, scanning the forest and canopy for animals. For each observation, we recorded the distance along the transect and estimated the distance from the transect to the individual animal or center of an animal group following standard distance sampling protocol (Buckland et al. 2001). To survey birds, we conducted point counts at 200-m intervals along the transects. Upon arrival at the point count station, observers waited for $2 \mathrm{~min}$ and then recorded visual observations of birds and the distance from the bird to the observer. Although we surveyed several bird species, we only present data and results for large frugivorous and insectivorous birds for which we are confident that our survey methods were robust. In addition to observations of animals, we also assessed 
hunting pressure by counting hunters, shotgun shells, wire snares, and camp fires encountered along transects.

\section{Environmental variables}

We measured canopy openness and light availability along transects with hemispherical canopy photographs. Photographs were taken every $250 \mathrm{~m}$ along a transect, $30 \mathrm{~cm}$ above the ground, in uniformly overcast conditions in the early morning or late afternoon with a leveled Nikon Coolpix P5000 camera body and Nikon FC-E8 Fisheye converter lens (Nikon, Tokyo, Japan). We analyzed images for the percentage of transmitted diffuse light and canopy openness using Gap Light Analyzer 2.0 (Frazer et al. 2001).

The 30 1-ha tree plots were used to examine whether forest structure influences animal abundance and distribution. Within each plot, we tagged, measured, and mapped all trees greater than $10 \mathrm{~cm}$ diameter at breast height (dbh). Voucher specimens were collected for each tree so that they could be later identified to species (Harris and Wortley 2008). For each tree, we also recorded the presence/absence of lianas in the crown and the canopy status of the tree (understory, midstory, canopy, and emergent). In addition, we quantified canopy openness and light availability for each plot, averaging the values of four hemispherical photographs taken from the center of each quadrant of the plots. Canopy heterogeneity was calculated for each plot and each transect as the standard deviation of canopy openness for the plot or transect.

We quantified fruit availability in each of the 30 plots by collecting fruits and seeds in $211-\mathrm{m}^{2}$ traps. Seven seed traps were centered along three lines at 25, 50, and $75 \mathrm{~m}$ from the plot border, with $10 \mathrm{~m}$ separating traps from one another. The same day that a transect was walked, we collected the seed trap contents from its adjoining plot. All seeds and fruits were counted and identified to species. When unknown fruits and seeds were collected, we searched the canopy over the seed trap for fruit, using the tagged trees to identify the propagule. For each plot, we estimated its monthly fruit abundance as the mean density of fruits per square meter.

\section{Overview of data analysis}

With the objective of examining how anthropogenic disturbance, environmental variables, and geographical position influence the densities of tropical forest species and guilds, we undertook a five-part approach to data analysis. First, because we had collected data on multiple environmental variables in each plot, we summarized the data into fewer variables using principal components analysis (PCA). These summarized variables were used as explanatory variables in later analyses. Second, we estimated densities of each animal species relative to the forest type (logged and hunted, logged and unhunted, and unlogged and unhunted forest) using Distance 5.0 software (Thomas et al.
2006) to assess whether species densities varied with disturbance. Third, we used RLQ analysis, a three-table ordination method, to assess the variables that could drive these differences in species densities across sites (Doledec et al. 1996, Ribera et al. 2001, Dray et al. 2002). The advantage to RLQ analysis is that both species traits and environmental conditions affected by disturbance, as well as their interrelationships, can be assessed (Cleary et al. 2007). Like other ordination techniques, RLQ analysis is largely descriptive and useful for looking at patterns, but not for quantifying the effects of specific variables. Therefore, as a fourth step, we examined the effects of disturbance, geographic position, and environmental variables by modeling these factors in relation to observations of animals of each of eight animal guilds. Like most field surveys of tropical animals, our data set included a high abundance of zero values (i.e., transects where we did not observe a particular species). Therefore, we employed zero-inflated Poisson (ZIP) models (described in detail in ZIP models to model animal guild densities) to model densities of animal guilds. We used Bayesian inference with Markov chain Monte Carlo (MCMC) simulation, implemented through WinBUGS version 1.4.1 (Spiegelhalter et al. 2003), to estimate posterior distributions of model parameters. Although Bayesian inference offers several advantages over frequentist and information-theoretic methods, our primary motivation was that MCMC methods could estimate parameters, especially random effects, when other methods tend to fail (Bolker et al. 2009). Bayesian MCMC gives similar answers to maximum-likelihood approaches when data sets are highly informative and little prior knowledge is assumed (i.e., when the priors are weak). We fitted two models for each of the animal guilds: (1) a "full model" that included all explanatory variables and (2) a "disturbance model" that excluded geographic location variables (longitude and latitude). We took this two-model approach because longitude and latitude were correlated with hunting and logging disturbance, thus they absorbed most of the variation and masked the effects of disturbance. Fifth, we evaluated the effects of logging, hunting, and logging and hunting on the animal guilds by (1) assessing the significance of differences between guild-specific posterior densities for each forest type and (2) representing the overall effect of logging, hunting, and logging and hunting as log-ratios of guild densities.

With the exception of the ZIP models and estimation of species density, all statistical analyses and graphing were performed with the R Language, version 2.7.1 ( $\mathrm{R}$ Development Core Team 2008).

\section{Ordination analysis of habitat structure}

To quantify variation in habitat structure among sites, we summarized the plot data (presence/absence of lianas, number of trees, number of tree species, number of secondary forest trees, mean and standard deviation of tree dbh, number of understory, midstory, canopy, 
and emergent trees, and percentage of diffuse light) into fewer variables using PCA. Three axes captured $95 \%$ of the variance and explained the main forest structure gradients (Fig. 3). The first axis (51\% of the variance) distinguished a gradient in the number of trees in a plot, with the number of understory, emergent, and canopy trees contributing to the number of trees. The second axis ( $31 \%$ of the variance) identified a forest structure gradient in the number of lianas in the plot, with understory trees supporting few lianas relative to canopy trees. Finally, the third axis (10\% of the variation) separated the number of understory trees from the number of canopy trees. We refer to these variables in subsequent analyses as "number of trees," "number of lianas," and "understory."

\section{Distance analysis of species densities}

We assess differences in species density across the three forest types through the application of designbased stratified distance-sampling methods. Using Distance 5.0, we estimated animal densities and calculated their associated coefficients of variation and $95 \%$ confidence intervals. To ensure robust estimation of detection and an effective strip half-width, the strip extending on either side of the transect line such that as many animals are seen beyond the strip as are missed within it, we calculated densities for species for which we gathered at least 40 observations per forest type and truncated observations farthest from each transect (Buckland et al. 2001). We fitted detection functions to the data sequentially with half-normal, uniform, and hazard-rate key functions combined with cosine, Hermite polynomial, and simple polynomial adjustment terms (Buckland et al. 2001). The best model was selected on the basis of the lowest Akaike information criterion (AIC) score. We examined model fit with chisquare goodness-of-fit tests.

\section{$R L Q$ analysis to link species traits with environmental characteristics}

To quantitatively assess the relationship between animal species traits and environmental characteristics of the plots, we used RLQ analysis (Doledec et al. 1996, Ribera et al. 2001, Dray et al. 2002). RLQ analysis relates a plot-by-variable table $(\mathrm{R})$ to a species-by-traits table $(\mathrm{Q})$, with a plot-by-species table (L) serving as a link between $\mathrm{R}$ and $\mathrm{Q}$. For animal species traits we included body size (small, $<5 \mathrm{~kg}$; small-to-medium, $<10$ $\mathrm{kg}$; medium, $<50 \mathrm{~kg}$; large, $>50 \mathrm{~kg}$ ) as reported in Kingdon (1997); feeding guild (browser, frugivore, frugivore-granivore, granivore, grazer, insectivore) from Gautier-Hion et al. (1985), Clark et al. (2001), Poulsen et al. (2001, 2002), and Morgan and Sanz (2006); and protected status (unprotected, partially protected, protected) according to the Congo hunting laws. For environmental traits we included type of disturbance (hunting, logging), fruit abundance, number of signs of hunting, mean $\mathrm{dbh}$ of trees $>10 \mathrm{~cm}$, canopy heteroge- $\triangle$ Logged, hunted forest

- Logged, unhunted forest

+ Unlogged, unhunted forest
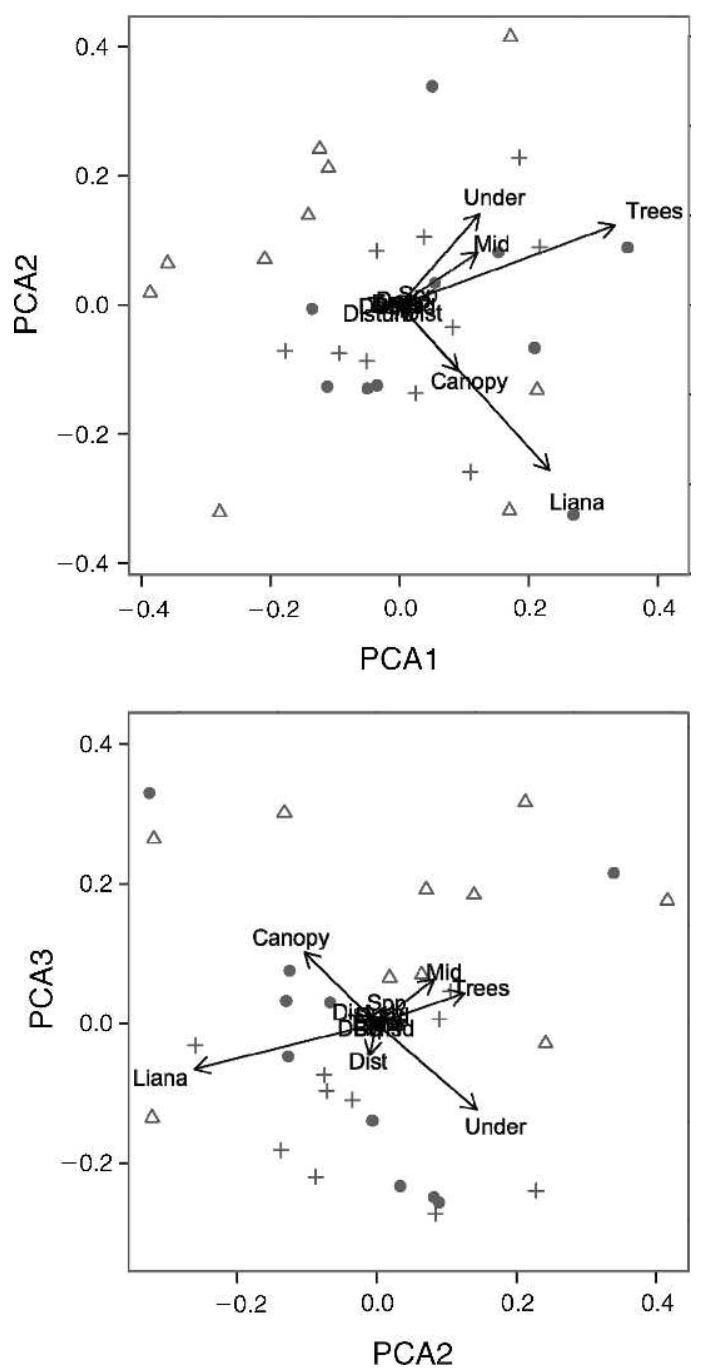

FIG. 3. Ordination based on principal components analysis (PCA) of 30 1-ha plots showing the first, second, and third axes. The biplot shows sites and environmental variables. Transects within sites are designated with different symbols (see key). Arrows represent the most important environmental factors: Under (number of understory trees), Mid (number of midstory trees), Canopy (number of canopy trees), Liana (number of lianas), Disturb (number of secondary species), and Dist (distance of plot from village). Other variables that were included in the PCA, but did not importantly differentiate the plots, included the number of trees (Trees), number of dead trees (Dead), average dbh (DBH), standard deviation of the average dbh (Hetero), and the percentage of transmitted light in the plot (Light). These variables are clumped at the center of the biplots.

neity, number of trees, number of trees topped by lianas, and number of understory and canopy trees.

Three separate ordinations of the $\mathrm{R}$ (environmental variables), $\mathrm{L}$ (species composition), and $\mathrm{Q}$ (species traits) tables were performed prior to the co-inertia analysis, a 
multivariate method for coupling two tables. First, the species abundance table (i.e., L table), containing the number of individuals of each species occurring at each transect, was analyzed by correspondence analysis (CA). Only species with five observations or more were included in the analyses due to the sensitivity of CA to "rare" species (Lesica and Cooper 1999). We also conducted the CA on the $\log _{10}$-transformed abundances of species, but it did not alter the overall results. The site and species scores were used to link the R and Q tables, as sites are shared by the $\mathrm{R}$ and $\mathrm{L}$ tables and species are shared by the Q and L tables (Ribera et al. 2001, Dray et al. 2002, Hausner et al. 2003, Choler 2005). Next, the relationship between plots and environmental attributes (i.e., the R table) was analyzed. For the quantitative set of variables PCA was applied using weights obtained with the CA of species, thereby linking the $\mathrm{R}$ to the $\mathrm{L}$ table. The final step in this initial procedure was the analysis of the Q table of categorical species traits with row weights obtained with the $\mathrm{CA}$ of species using multiple correspondence analysis (MCA; Tenenhaus and Young 1985). After these three steps a single inertia analysis was performed on the cross-matrix of R, L, and Q. Co-inertia analysis selects axes that maximize covariance between the $\mathrm{R}$ and $\mathrm{Q}$ tables. As a result, the environmental attributes are directly related to species traits. RLQ analysis is a symmetric analysis, in the sense of finding scores that are optimally related to each table, without emphasizing environmental variables or species traits. All analyses were carried out using the ADE4 software package within R (Dray et al. 2007).

\section{ZIP models to model animal guild densities}

We assessed the importance of disturbance (hunting and logging), geographic position, environmental variables, and fruit abundance on animal density by modeling these factors in relation to observations of animals for each of eight guilds. Modeling the number of animals in a given guild at a particular point in time (month) and space (forest type) is generally done by fitting models such as a generalized linear mixed model (GLMM) or a generalized additive model (GAM) using a Poisson distribution. However, a distinguishing characteristic of data from surveys is their tendency to contain a large proportion of zeros. Examination of the frequencies of counts of animal observations demonstrated that the data included more zeros than can be expected from either a Poisson or a negative binomial distribution. A high frequency of zeros can arise in several ways (Kuhnert et al. 2005, Martin et al. 2005a). Structural zeros result from an ecological effect; for example, a strong seasonal or environmental gradient causes some sites to have no animals present in one season or under particular conditions (e.g., heavy hunting). Random zeros (also referred to as sampling zeros) result from observer error and study design: the observer fails to detect the species or the species occurs but is not present during the survey. These are false negative errors and arise when a species is not recorded when it is in fact present. Modeling of data with a high frequency of zeros can lead to spurious results if these factors are not taken into account (reviewed in Martin et al. 2005b).

Although multiple approaches can be used for modeling high frequencies of zeros (e.g., hurdle model, negative binomial model), when random zeros are present in the data, a zero-inflated mixture modeling approach is required (MacKenzie et al. 2002, Tyre et al. 2003). Our data certainly included sampling zeros because a species was sometimes not recorded on a transect at time $t$, even though it had been recorded at times $t-1$ and $t+1$. Therefore we employed a zeroinflated Poisson model (ZIP) composed of a point mass at zero and a Poisson distribution (Lambert 1992). Using this approach, we modeled the probability that a zero comes from a Poisson distribution or alternatively as a structural zero.

The mixture model is specified as follows:

$$
\begin{aligned}
& \operatorname{Pr}\left(y_{i j k}=0 \mid x, z\right) \\
& \quad=1-p\left(x_{i j k}\right)+p\left(x_{i j k}\right) \exp \left(-\lambda\left(z_{i j k}\right)\right) \\
& \operatorname{Pr}\left(y_{i j k}=r \mid x, z\right) \\
& \quad=p\left(x_{i j k}\right) \frac{\exp \left(-\lambda\left(z_{i j k}\right)\right) \lambda\left(z_{i j k}\right)^{r}}{r !} \quad r=1,2, \ldots
\end{aligned}
$$

where

$$
\begin{aligned}
\operatorname{logit}\left(p\left(x_{i j k}\right)\right) & =\boldsymbol{\beta}_{0} x_{i j k}+\boldsymbol{\gamma}_{0 i j k} \\
\log \left(\lambda\left(z_{i j k}\right)\right) & =\boldsymbol{\beta}_{1} z_{i j k}+\boldsymbol{\gamma}_{1 i j k}+\log \left(\Phi_{i j}\right) .
\end{aligned}
$$

In both equations, $p\left(x_{i j k}\right)$ represents the probability that an observation $i$ is modeled as a Poisson distribution. Above, $\lambda\left(z_{i j k}\right)$ represents the mean expected number of individuals at transect $j$ and month $k$ and is expressed as a function of the explanatory variables, $z$, through a log transformation. Similarly, $p\left(x_{i j k}\right)$ can be expressed as a function of the explanatory variables $x$, using a logit transformation. Here the parameters $\boldsymbol{\beta}_{0}$ and $\boldsymbol{\beta}_{1}$ are vectors representing the coefficients estimated for explanatory variables, $x_{i j k}$ and $z_{i j k}$ (fixed effects), and $\gamma_{0 i j k}$ and $\gamma_{1 i j k}$ are vectors for the grouping variables (random effects). To model animal density, we included the area sampled, $\Phi_{i j}$, as an offset. We calculated $\Phi_{i j}$ for the $i$ th species and $j$ th transect by multiplying the distance walked along a transect by twice the speciesspecific effective strip width estimated by Distance 5.0. We did not include a constant intercept term in the models as its inclusion sometimes made parameter optimization difficult. 
We related the observations of animals of each guild to the following explanatory variables $\left(x_{i j k}\right.$ and $\left.z_{i j k}\right)$ : (1) site (logged/hunted, logged/unhunted, unlogged/unhunted); (2) geographical coordinates (longitude and latitude); (3) number of trees (PCA1); (4) number of lianas (PCA2); (5) number of understory trees (PCA3); (6) canopy heterogeneity (standard deviation of transect diffuse light); and (7) monthly fruit abundance. All continuous explanatory variables were transformed into $z$ scores for analysis (Gelman and Hill 2007). So that fruit abundance would reflect the actual diet of an animal guild, we used diet lists from the literature to categorize fruit species by the types of animals that consumed them (Gautier-Hion et al. 1985, White et al. 1993, Tutin et al. 1997, Whitney et al. 1998, Clark et al. 2001, Poulsen et al. 2001, 2002, Morgan and Sanz 2006). We included the month that the survey was conducted and species as random effects $\left(\gamma_{0 i j k}\right.$ and $\left.\gamma_{1 i j k}\right)$.

Bayesian inference with MCMC simulation was used to estimate posterior distributions of model parameters and test for significance. Statements of significance are made in the Bayesian context where a "significant" effect indicates that the $95 \%$ credible interval corresponding to that effect does not include zero and an estimate that is "significantly less than" a proposed value has 5\% probability of being equal to or greater than the proposed value. For the ZIP models, we used weakly informative, normally distributed priors for fixed effects, half-Cauchy priors for random effects, and gamma priors on the precisions of the variance components (Gelman and Hill 2007). The "zeros trick" allowed the specification of the truncated Poisson distribution (Spiegelhalter et al. 2003, Kuhnert et al. 2005, Martin et al. 2005a, b). We fit our models using the software WinBUGS version 1.4.1 (Spiegelhalter et al. 2003). For each model, we achieved convergence after 50000 iterations (the "burn-in") and based summary statistics on an additional 50000 iterations. We ran three chains to monitor convergence based on variance components of multiple sequences and assessed convergence by visual inspection and with Gelman-Rubin statistics from the R contributed package coda (Plummer et al. 2005). For point estimates, we extracted the means of the posterior distributions and we derived $95 \%$ credible intervals based on the observed quantiles from the MCMC replicates.

\section{Estimation of mean guild abundance for each forest type}

To get the estimate of mean guild abundance for each forest type, we held all other covariates at their mean values and we multiplied the ZIP mixing probability, the probability that the number of individuals along a transect has a Poisson distribution (i.e., is not structurally zero), by the predicted density of individuals generated from a Poisson distribution. We compared the density of an animal guild between forest types by examining the $95 \%$ interval of the differences of the posterior densities of each forest type (e.g., Density l,h $_{-}$
Density $_{1, u h}$, where subscript "l" indicates logged, subscript "h" indicates hunted, and subscript "uh" indicates unhunted): when the $95 \%$ probability range of differences includes 0 there is no difference in guild density between two forest types. We then estimated the overall effect of logging, hunting, and logging and hunting as log-ratios of guild densities by dividing the posterior mean abundance of a guild at the disturbed site from the posterior mean abundance of the site where that disturbance was not present:

$$
\begin{aligned}
\text { Effect }_{\mathrm{l}} & =\log \left(\text { Site }_{\mathrm{l}, \mathrm{uh}}\right) / \log \left(\text { Site }_{\mathrm{ul}, \mathrm{uh}}\right) \\
\text { Effect }_{\mathrm{h}} & =\log \left(\text { Site }_{\mathrm{l}, \mathrm{h}}\right) / \log \left(\text { Site }_{\mathrm{l}, \mathrm{uh}}\right) \\
\text { Effect }_{\mathrm{l}+\mathrm{h}} & =\log \left(\text { Site }_{\mathrm{l,h}}\right) / \log \left(\text { Site }_{\mathrm{ul}, \mathrm{uh}}\right) .
\end{aligned}
$$

Therefore, here we define the effect of a disturbance for an animal guild as the ratio of the guild density in disturbed and undisturbed forest. This differs from studies where the effect is the estimate of animal abundance before and after the disturbance (e.g., Crome et al. 1996). Note that due to the missing forest type (unlogged, hunted), our estimate of the effect of hunting is actually the estimate of hunting in logged forest.

RESUlts

\section{Densities of animal species}

We recorded 9811 direct observations of animal groups (47 179 animals) in $2861 \mathrm{~km}$ of transects ( $n=$ 1154 passages along transects) between June 2005 and May 2007 (Fig. 2). From these data, we estimated the densities of 19 species for each of the three forest types (Table 1). Design-based distance sampling estimates of abundance demonstrated large differences in estimated densities among forest types for several species. All four monkey species (Lophocebus albigena, Cercopithecus cephus, C. nictitans, and C. pogonias), ape species (Gorilla gorilla and $P$. troglodytes), blue duiker (Cephalophus monticola), and medium duikers (Cephalophus spp.) tended to have highest densities in unlogged, unhunted forest and lowest densities in logged, hunted forest. By contrast, elephant (Loxodonta africana) density was highest in logged, hunted forest and logged, unhunted forest. Large frugivorous birds (Bycanistes albotibialis, B. fistulator, Ceratogymna atrata, Corythaeola cristata, and Psittacus erithacus) tended to have highest densities in logged, hunted forest, whereas insectivorous birds (Tockus albocristatus, $T$. cameras, and $T$. fasciatus) had the highest densities in either the logged, unhunted or logged, hunted forest. Densities of both squirrel species (Funisciurus lemniscatus and Protoxerus stangeri) were highest in logged, hunted forest.

\section{Relationship between species and environmental variables}

The RLQ analysis revealed a significant association between environmental variables and species traits. We 
TABLE 2. Results of multivariate analyses to assess the relationship between animal species traits and environmental characteristics of the plots.

\begin{tabular}{lll}
\hline \hline \multicolumn{1}{c}{ Statistic } & \multicolumn{1}{c}{ Axis 1 } & \multicolumn{1}{c}{ Axis 2 } \\
\hline A) Separate analyses & & \\
R/PCA & $2.60(28.9 \%)$ & $2.11(23.4 \%)$ \\
L/CA & $0.10(47.5 \%)$ & $0.03(1.9 \%)$ \\
Q/MCA & $2.39(23.9 \%)$ & $1.82(18.2 \%)$ \\
B) RLQ analysis & & \\
Eigenvalues & $0.148(82.7 \%)$ & $0.007(5.0 \%)$ \\
Covariance & 0.39 & 0.08 \\
Correlation & 0.21 & 0.05 \\
Projected inertia & & \\
$\quad$ Table R & $1.95(75.0 \%)$ & $1.49(70.5 \%)$ \\
$\quad$ Table Q & $1.79(74.6 \%)$ & $1.76(96.8 \%)$ \\
\hline
\end{tabular}

Notes: (A) For separate analyses: eigenvalues and percentages of the total inertia are accounted for by axes 1 and 2 . Ordinations were a principal components analysis (PCA) of R, multiple correspondence analysis (MCA) of $\mathrm{Q}$, and a correspondence analysis (CA) of L. (B) Summary of RLQ analysis: eigenvalues and percentages of the total co-inertia accounted for by RLQ axes 1 and 2, covariance and correlation between the site scores constrained by the environmental variables in $\mathrm{R}$ and species' scores constrained by the traits in Q, projected inertia of table R and Q onto the first two RLQ axes, and percentage of the inertia obtained in the separate analysis of $\mathrm{R}$ and Q along the same axes (e.g., RLQ axis 1 accounts for $53.5 \%$ of the projected inertia of $\mathrm{R}$ along PCA axis $1[(100 \times 1.39) / 2.60$ $=53.5 \%]$ ).

consider the first two RLQ axes, which together explained $87.7 \%$ of variance in the analysis. Because the RLQ analysis represents the partial ordination of the environmental characteristics, the species abundances, and the species traits, we compared the proportion of variance attributed to each matrix to that resulting from their separate analyses. The first axis of the RLQ analysis accounted for $82.7 \%$ of the variance and for $53.5 \%$ of the variance in environmental variables and $56.0 \%$ of the variance in species traits (Table 2). The second axis of the RLQ analysis accounted for only $5.0 \%$ of the variance and for $56.0 \%$ of the variance in environmental variables and $79.2 \%$ of the variance in species traits. Overall, these results showed that the structure of tables $\mathrm{R}$ and $\mathrm{Q}$ were related to the species abundance gradients in $\mathrm{L}$.

Along axis 1, logged, hunted forest with a low abundance of understory trees contained species with a different set of traits than logged, unhunted and unlogged, unhunted forest (Fig. 4). In addition to having a greater number of hunting signs, logged, hunted forest was characterized by having a greater number of secondary tree species. This forest type tended to be occupied by small insectivorous and granivorous species, whereas unhunted forest tended to contain larger species and more grazers and browsers. Axis 2 explained very little of the variance, but separated plots and species by forest structure. Plots with high mean dbh were more heterogeneous and separated from those with greater numbers of canopy trees and a more even canopy cover. Abundance of large browsers was higher in the more heterogeneous forest and separated from the rest of the animal community.

\section{Determinants of guild densities}

The ZIP models identified the factors that most strongly determine densities of animal guilds. The absence component of the ZIP model, quantifying the probability of a structural zero, varied across guilds (Supplements 1 and 2). Here we focus on the abundance component of the models and the effects of hunting, logging, geographical location, forest structure, and fruit abundance on the densities of guilds. Effects are in units of guild densities, with variables that did not contribute strongly to abundance centered on zero (Fig. 5). Below we present the results of the full model, which includes all factors, and the disturbance model, which excludes latitude and longitude.

In the full ZIP model, guild densities often varied along a latitudinal gradient with the effect of latitude being stronger than effects of many other explanatory variables (Fig. 5, Supplement 1). Monkey, pig, duiker, and ape densities increased with latitude; whereas frugivorous bird density decreased with latitude. In this model, pairwise comparisons of guild densities predicted for each forest type differed significantly $58 \%$ of the time (14 of 24 comparisons), as assessed by the distribution of differences in guild densities between forest types (Table 3). Notably, differences in guild densities between forest types often occurred in an unexpected direction. For example, our design-based results found both duiker and monkey species to have lowest densities in logged, hunted forest compared to other forest types (which is in accordance with field observations). However, the full ZIP model predicted logged, hunted forest to have a significant positive effect on guild densities relative to one of the other forest types (unlogged, unhunted forest for duikers, logged, hunted forest for monkeys). These results suggest that the effects of disturbance were confounded by the correlation between geographic coordinates and hunting indices (latitude: $r=-0.66$, df $=28, P<0.001$; longitude: $r=-0.53, \mathrm{df}=28, P=0.002)$ : the intensity of hunting and the presence of logged forest both decreased with greater distance from the main logging village along a northeast gradient. With spatial coordinates absorbing most of the effects of logging and hunting, any differences in guild densities among the three forest types were driven by other unmeasured variables.

In the full model, the densities of several animal guilds varied according to forest structure and fruit resources (Fig. 5). Elephant density was predicted to be higher in forest with a heterogeneous canopy with relatively high numbers of large trees. Ape density was also higher in forest with variable canopy cover and with more lianas. Densities of frugivorous bird and monkey were higher in forest with a more homogenous canopy, with frugivorous bird having higher densities in forest without lianas and monkey having higher densities in forest with lianas. 

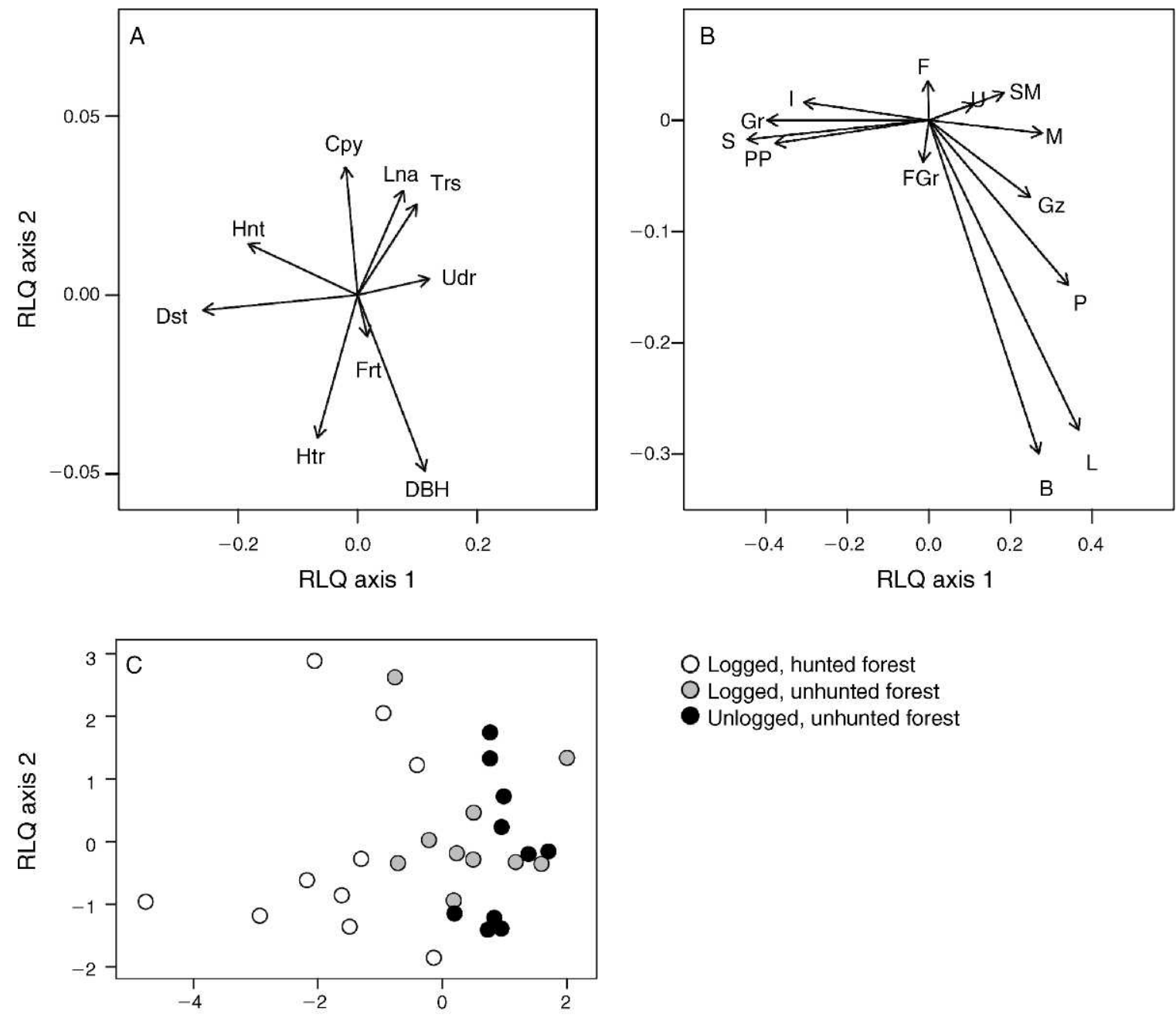

RLQ axis 1

FIG. 4. Display of (A) environmental variables, (B) species traits, and (C) plots along the first two RLQ axes. In panel (C), each plot is represented by a symbol representing the forest type. Abbreviations for plot characteristics include: Dst (disturbance), Frt (fruit abundance), Hnt (signs of hunting), DBH (mean diameter at breast height of trees $>10 \mathrm{~cm}$ dbh), Htr (canopy heterogeneity), Trs (number of trees), Lna (number of trees topped by lianas), Udr (number of understory trees), Cpy (number of canopy trees). Abbreviations for species traits include size (S, small, $<5 \mathrm{~kg}$; SM, small-to-medium, $<10 \mathrm{~kg}$; M, medium, $<50 \mathrm{~kg}$; L, large, $>50$ $\mathrm{kg}$ ), feeding guild (B, browser; F, frugivore; FGr, frugivore-granivore; Gr, granivore; Gz, grazer; I, insectivore), and protected status (U, unprotected; PP, partially protected; $\mathrm{P}$, protected).

Both monkey and frugivorous bird density increased on transects with increased fruit abundance.

The disturbance model (excluding latitude and longitude) allowed us to estimate the effects of hunting and logging by comparing guild densities among the three types of forest (see Methods). After running the ZIP models, we predicted guild density for the three forest types, keeping all other variables at their mean values, and then calculated the effects of hunting, logging, and hunting and logging (Fig. 6). Hunting decreased densities of five of the eight guilds: only elephants, frugivorous birds, and squirrels did not have significantly lower densities in hunted forest relative to unhunted forest. Hunting had the largest negative effect on apes, reducing their density by $61 \%$, and the largest positive effect on frugivorous birds, increasing their density by $77 \%$. The densities of apes, duikers, monkeys, pigs, and frugivorous birds were lower in logged forest, but bird and elephant densities were higher in logged than unlogged forest. The differences in guild densities between logged and unlogged forest ranged widely: pig densities were $44 \%$ lower in logged forest, whereas insectivorous bird densities were $90 \%$ higher. Compared to unlogged, unhunted forest, the combination of logging and hunting resulted in lower guild densities for ape, duiker, monkey and pig, and higher guild densities for elephant, bird, and squirrel (Fig. 6). 

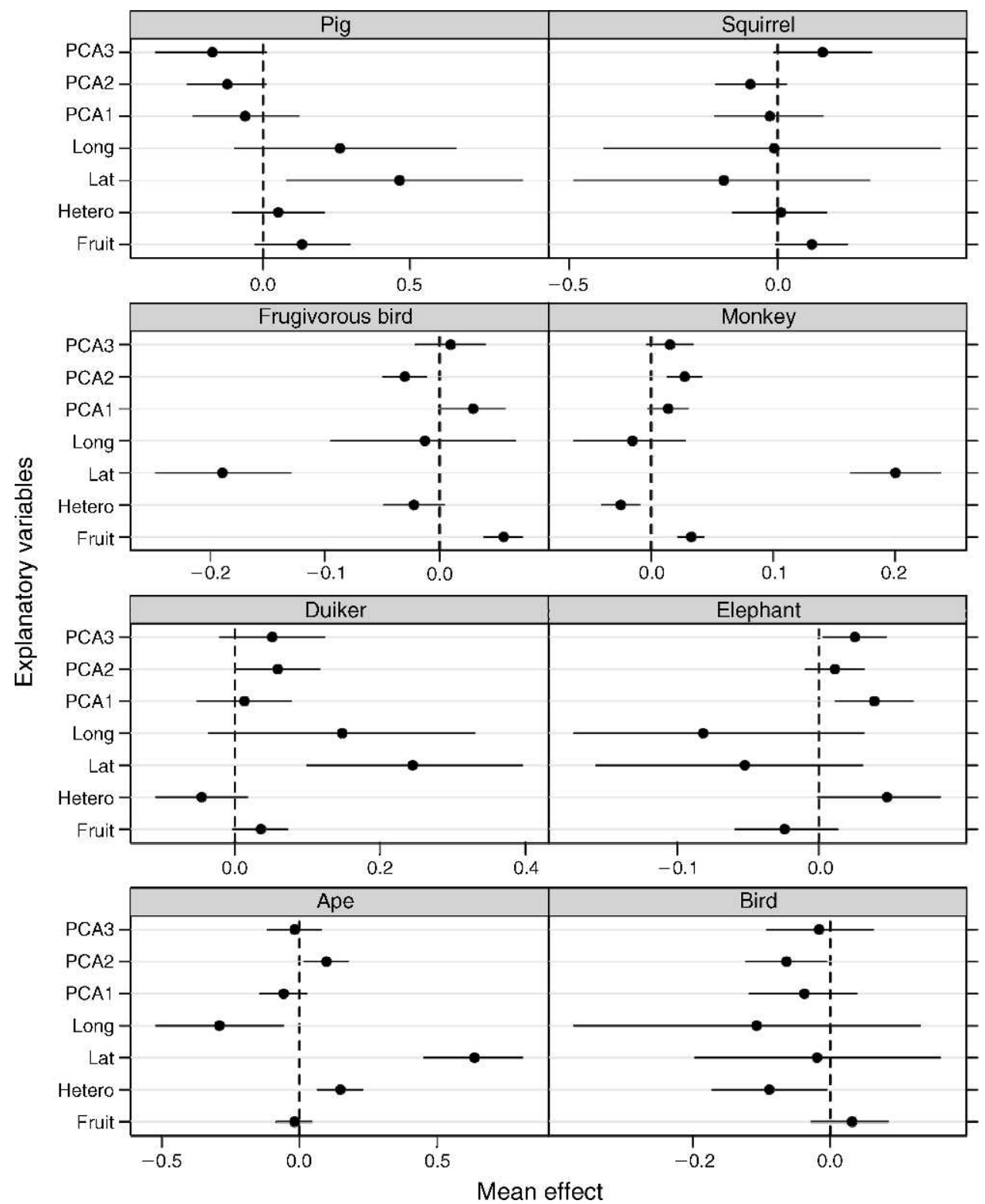

FIG. 5. Dotplot of estimates of explanatory variables from the full models for animal guilds, depicting the effects of environmental (principal component axis 1 [PCA1], PCA2, PCA3, and Hetero), spatial (Lat, Long), and resource (Fruit) variables on guild densities. Points are the posterior means from the zero-inflated Poisson (ZIP) models, and bars are $95 \%$ credible intervals.

\section{DisCUSSION}

Our results suggest that densities of animal guilds vary more strongly in relation to disturbance type than with variation in forest structure, canopy cover, and fruit abundance. By comparing sites differentially affected by hunting and logging, we found that disturbance type differentially impacted animal guilds, with some responding positively and others responding negatively. The combination of hunting and logging exacerbated population declines of medium- and large-bodied animal guilds (ape, duiker, monkey, and pig) and shifted the composition of the animal community toward squirrels and birds.

Selective logging modifies both the large-scale architecture of the forest and the local-scale environmental characteristics, both of which can potentially influence densities of animal populations. At the landscape level, selective logging creates felling gaps during timber extraction and fragments the forest during the construction of roads and skid trails (Asner et al. 2004). Selective logging in the Congo Basin usually only damages 10 $20 \%$ of the logged area (Durrieu de Madron et al. 2000, Van Gemerden et al. 2003), but canopy damage can be 
TABLE 3. The $95 \%$ probability range of differences in animal guild densities due to forest type assessed from the posterior densities.

\begin{tabular}{|c|c|c|c|}
\hline Guild & Comparison & Full model & Disturbance model \\
\hline \multirow[t]{3}{*}{ Ape } & 1, hunting & $0.15,0.74$ & $-0.76,-0.31$ \\
\hline & 2 , logging + hunting & $-0.36,0.60$ & $-0.76,-0.34$ \\
\hline & 3 , logging & $-0.64,0.12$ & $-0.21,0.09$ \\
\hline \multirow[t]{3}{*}{ Duiker } & 1 , hunting & $-0.19,0.25$ & $-0.64,-0.31$ \\
\hline & 2, logging + hunting & $0.13,0.67$ & $-0.53,-0.19$ \\
\hline & 3 , logging & $0.26,0.57$ & $0.01,0.25$ \\
\hline \multirow[t]{3}{*}{ Elephant } & 1 , hunting & $-1.10,0.20$ & $-0.64,-0.31$ \\
\hline & 2, logging + hunting & $-2.66,-0.12$ & $-0.53,-0.19$ \\
\hline & 3 , logging & $-2.24,-0.04$ & $0.01,0.25$ \\
\hline \multirow[t]{3}{*}{ Frugivorous bird } & 1 , hunting & $-0.028,0.16$ & $0.42,0.53$ \\
\hline & 2 , logging + hunting & $-0.20,0.02$ & $0.41,0.55$ \\
\hline & 3 , logging & $-0.24,-0.04$ & $-0.03,0.08$ \\
\hline \multirow[t]{3}{*}{ Bird } & 1 , hunting & $-0.64,-0.10$ & $-0.37,-0.06$ \\
\hline & 2 , logging + hunting & $-0.87,0.40$ & $0.10,0.51$ \\
\hline & 3 , logging & $-0.23,0.62$ & $0.4,0.70$ \\
\hline \multirow[t]{3}{*}{ Monkey } & 1 , hunting & $0.08,0.23$ & $-0.120,-0.13$ \\
\hline & 2, logging + hunting & $-0.26,-0.03$ & $-0.62,-0.54$ \\
\hline & 3 , logging & $-0.36,-0.24$ & $-0.44,-0.39$ \\
\hline \multirow{3}{*}{ Squirrel } & 1 , hunting & $0.02,0.89$ & $0.40,0.86$ \\
\hline & 2 , logging + hunting & $-0.72,0.80$ & $0.30,0.76$ \\
\hline & 3 , logging & $-0.97,0.05$ & $-0.31,0.10$ \\
\hline \multirow[t]{3}{*}{ Pig } & 1 , hunting & $0.94,2.32$ & $-0.75,-0.02$ \\
\hline & 2 , logging + hunting & $1.42,3.32$ & $-0.57,0.18$ \\
\hline & 3 , logging & $0.31,1.57$ & $-0.04,0.47$ \\
\hline
\end{tabular}

Notes: For each animal guild, the comparisons are (1) $\beta_{1, \mathrm{~h}}-\beta_{\mathrm{l}, \mathrm{uh}}$, (2) $\beta_{\mathrm{l}, \mathrm{h}}-\beta_{\mathrm{ul}, \mathrm{uh}}$, and (3) $\beta_{\mathrm{l}, \mathrm{uh}}-$ $\beta_{\mathrm{ul}, \mathrm{uh}}$, where $\beta$ is the effect of a forest type on guild density and the subscripts describe the forest type (l, logged; h, hunted; uh, unhunted; ul, unlogged). When the $95 \%$ probability range of differences does not include 0 (values in boldface), there is a significant difference in guild density between two forest types. The full model includes latitude and longitude as factors, whereas the disturbance model excludes spatial coordinates.

spatially distributed over the logged area, resulting in extensive fragmentation and soft edge effects in contiguous forest (Broadbent et al. 2008).

In this study we found the landscape-level effects of selective logging to more strongly influence densities of animal guilds than local-scale effects. Just the fact of being in a timber concession affected guild densities at a site more than the variation in environmental characteristics among sites within the concession. Fragmentation of the forest, and in particular roads, may be barriers to movement for some animals. Elephants avoid traversing unprotected roads (Blake et al. 2007),

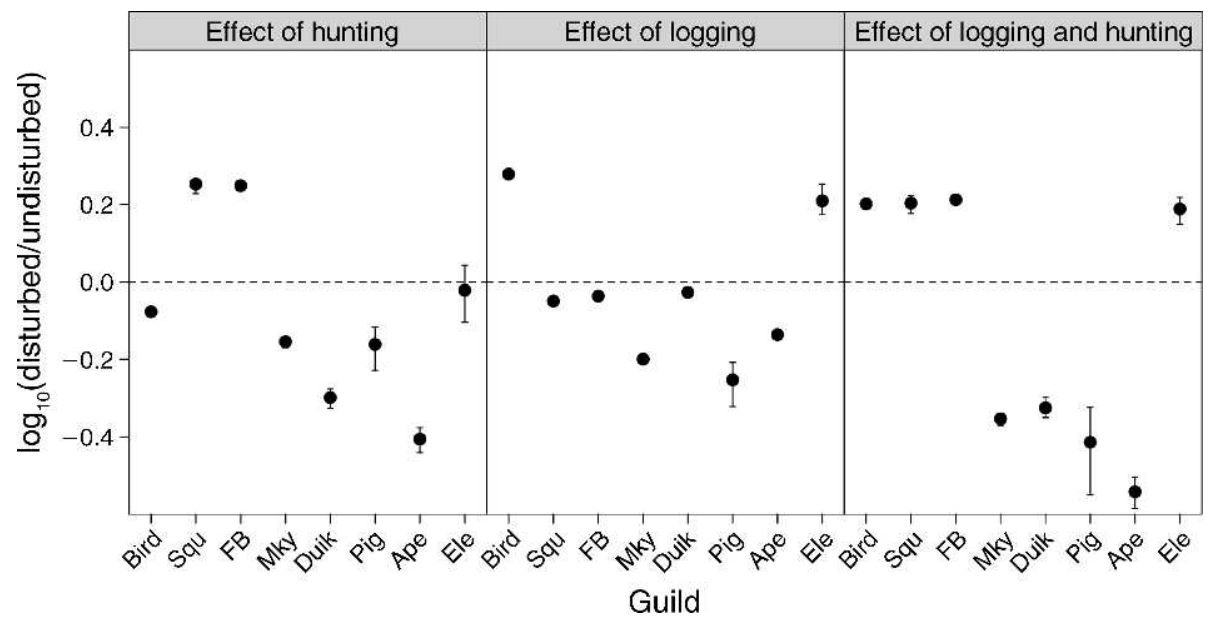

FIG. 6. The effect of hunting, logging, and hunting and logging together on guild density, where guild density is the density of all species within a guild. The effects of disturbances were estimated as log ratios of guild densities by dividing the posterior mean abundance of a guild at the disturbed site from the posterior mean abundance of the site where that disturbance was not present (e.g., Effect ${ }_{1}=\log \left(\right.$ Site $\left._{1, \text { uh }}\right) / \log \left(\right.$ Site $\left._{u l, u h}\right)$ where subscripts define disturbance type [1, logging; uh, unhunted; ul, unlogged]). Bars represent $95 \%$ credible intervals. Guilds are presented in order of increasing body mass: Bird, large insectivorous bird; Squ, squirrel; FB, large frugivorous bird; Mky, monkey; Duik, duiker; Pig; Ape; and Ele, elephant. 
and chimpanzees alter their behavior depending on their risk assessment of roads (Hockings et al. 2006). Some animals also avoid intense human-produced noise that could be associated with active logging operations and road activity (Rabanal et al. 2010).

At the local scale, logging opens the canopy and changes forest structure, which has cascading effects on the light regime, vegetation regeneration, and fruit production within the felling gap (Putz et al. 2001). Canopy cover and forest structure explained variation in densities for several guilds and are likely associated with the abundance of food resources. Notably, elephants and apes had higher densities in forest with a heterogeneous canopy that provides herbaceous food plants for elephants and gorillas (Barnes et al. 1991). In contrast, frugivorous and insectivorous birds and monkeys had higher densities in closed-canopy forest. Frugivorous bird density was higher in forest with low liana abundance, whereas monkey density was higher in forest with abundant lianas, reflective of their more generalist diets and tendency to feed in the low and mid-canopy (Clark et al. 2001). In Uganda, monkey food availability was higher in unlogged than logged forest and supported higher densities of frugivorous monkeys (Rode et al. 2006). In our study, densities of frugivorous birds and monkeys increased on transects with increased fruit abundance. However, logged forest did not have significantly higher abundances of monkey or bird fruits (GLMM : monkey fruit in logged forest, $t=0.16, P=0.15$; bird fruit in logged forest, $t=-0.19, P=0.85)$. Large frugivorous birds tend to have comparatively specialized diets and therefore might be attracted to certain species, whereas monkeys are more generalist in their feeding behavior (Clark et al. 2001, Poulsen et al. 2001, 2002). The abundance of several tree genera known to be key fruit resources for birds were much higher in logged plots than unlogged plots (mean number of trees per plot in logged and unlogged plots: Cleistopholis spp., 3.5 vs. 0.8 trees; Macaranga spp., 14.1 vs. 4.0 trees; Musanga sp., 1.3 vs. 0 trees; Xylopia spp., 8.3 vs. 1.9 trees).

Moderate hunting pressure can also markedly alter the structure of mammal communities in central Africa (Fa et al. 2005, Laurance et al. 2006, Clark et al. 2009). In our study, despite low population pressure $(\sim 1$ person $/ \mathrm{km}^{2}$ ) and active enforcement of hunting laws, hunting reduced the densities of duiker, monkey, and pig by $50 \%, 30 \%$, and $31 \%$. These declines in guild densities are consistent with market surveys of bushmeat in the area, demonstrating them to be the most commonly hunted animals (Mockrin 2008, Poulsen et al. 2009). Other studies have found that hunting shifts animal community structure to be composed of higher proportions of birds and small mammals due to the harvest of larger-bodied animals (Jerozolimski and Peres 2003, Fa et al. 2005). Our results also demonstrate that densities of large-bodied animals (with the exception of ele- phants) are lower in hunted than unhunted forest. However, densities of large frugivorous birds, insectivorous birds, and squirrels were higher in hunted forest, suggesting that a decline in densities of larger-bodied guilds might release birds and squirrels from competition for resources.

\section{Can logged forest support populations of tropical animals?}

Whether or not forest degraded by logging can support tropical animal species depends on the standard that is applied. One standard is that logged forest must only maintain populations of species or guilds: as long as populations continue to exist the population size is of secondary importance. No local extinction occurred in our study; all species surveyed in unlogged forest were also found in logged forest. A second standard is that logged forest must support the same densities of species or guilds as unlogged forest. Our study provides no evidence that, even in the absence of hunting, selectively logged forest maintains similar population sizes for most animal guilds as unlogged forest. A third standard is that logged forest might possess lower densities of some guilds as long as ecological functions are maintained. This raises two issues. (1) If the chosen standard is the maintenance of population sizes, can we expect animal populations to return to densities similar to pre-logging situations or unlogged forest? (2) What are the consequences of different (either substantially lower or higher) abundances of tropical animals for forest maintenance and regeneration?

In this study, we selected forest areas that had been logged decades (25-30 years) earlier to examine the effect of logging on animal guilds after forest had had time to recover. Even so, we still detected and quantified differences in densities of several animal guilds in logged and unlogged forest. Thirty years was the maximum possible recovery time because timber extraction is planned on a 30-year rotation; in fact, the logging company has since logged the area for a second time. Clark et al.'s (2009) large-scale survey included forest logged from 1 to 30 years previously and demonstrated that species abundances responded nonlinearly with time since logging. Only ape abundances increased with time, whereas most ungulate densities started to decline $\sim 15$ years after logging. In a review of the recovery of faunal communities during forest regeneration, Dunn (2004) determined that species richness could be predicted to resemble that of mature forests after 2040 years, but that species composition takes substantially longer to recover. Our conclusion is that 30 years is not long enough for medium- and large-bodied species to return to the densities found in unlogged forest (and thus similar species composition of unlogged forest). We guess that in forest logged two or three times many species would take even longer to reach such densities. However, species recovery likely varies with different stages of forest regrowth and would be best assessed by surveying continually over decades. 
The time it takes animal communities to recover may determine the degree to which disruptions in ecological services affect tropical forests. If species composition of animal communities recovers within a few decades, degraded forest may help conserve animal species. On the other hand, if animal communities take much longer to recover, the recovery of plant communities and ecosystem processes may be slowed or fundamentally altered. Change in the abundance and composition of the animal community can have cascading effects on forest dynamics through the modification or loss of ecological services that contribute to forest regeneration. After disturbance, the identity of the residual fauna will determine how plant-animal reactions will play out (Wright 2003). For example, large-seed species may escape seed predation where the residual mammalian fauna is dominated by small rodents (Dirzo et al. 2007). Studies have also found the loss or reduction of large mammals by hunting to reduce seed dispersal rates for some plant species, to favor species dispersed abiotically and by birds and small mammals, and to alter seed banks and seedling and sapling recruitment (Wright et al. 2000, 2007a, b, Terborgh et al. 2008). Moreover, seemingly complementary species do not necessarily compensate for one another. Large frugivorous birds and arboreal monkeys in a Cameroonian forest had low dietary overlap and produced different seed shadow patterns, making it unlikely that the loss of arboreal monkeys from logging and hunting in this study could be replaced by the seed dispersal services of birds (Clark et al. 2001, 2005, Poulsen et al. 2002).

\section{Recommendations for management}

In this study we took advantage of a relatively long data set (two years of observations) for central African forest animals so that estimates of density are not biased by seasonal or phenological changes. We also only used direct observations of animals so species and guild densities do not include error introduced through estimates of nest and dung decay and production (Walsh and White 2005). Though we established transects over a large area $\left(3000 \mathrm{~km}^{2}\right)$, the spatial pattern of logging and hunting required that transects impacted by similar disturbances be grouped together. Both the intensity of hunting and presence of logged forest decreased along a northeastern gradient with distance from the village. This spatial gradient in disturbance was reflected in a latitudinal gradient in densities for monkeys, duikers, and apes. We attributed the gradient in guild densities to the effects of logging and hunting rather than topographic or floristic changes across the study area. This is justified because the topography of this part of northern Congo is flat, with little variation. In addition, except for a greater number of secondary trees in vegetation plots in logged forest, we observed no major changes in tree species composition along the geographic gradient. Recent surveys of central African mammal species at large spatial scales have found them to be more abundant with proximity to protected areas where logging and hunting do not occur (Blake et al. 2007, Clark et al. 2009, Stokes et al. 2010).

The implementation of large-scale surveys to assess the results of conservation activities and land use planning on tropical mammals is irreplaceable for evaluating the densities of the largest mammals, such as elephants and great apes, across entire parks and concessions that entail millions of hectares of forest (Blake et al. 2007, Clark et al. 2009, Stokes et al. 2010). We emphasize the importance of pairing large-scale surveys with smallerscale studies designed to decouple specific disturbances or management practices. For example, using methods that allowed us to survey multiple species, not just those species that leave long-lasting dung or nests, we were able to detect significant differences in species densities for small- and medium-bodied species (e.g., monkeys, duikers, and birds) that were not detected for elephant or apes. Our results suggest that large, endangered species may not always be good indicators of the health of the rest of the animal community because they tend to be more general in their habitat use, have more flexible diets, and be more mobile so that they can leave poor habitat for higher quality habitat. At our study site, elephants are a good example. Elephant densities were not affected by hunting, probably because of the active law enforcement focused on the protection of endangered species. Elephant densities were higher in logged forest, probably largely due to the higher abundance of saplings and secondary species in the forest and to a lesser extent to the presence of human crops next to villages that they sometimes raid for food. Detecting changes in small- and medium-bodied species is important as they not only serve important ecological functions such as seed dispersal, predation, and herbivory, but as game species they also provide protein and revenue for rural-based communities.

With most of the forests of central Africa either already logged or in the process of being exploited, degraded forest represents an increasingly important habitat for most tropical animals. With the recognition that tropical countries need timber revenues for development and the rural poor often rely on wildlife for their livelihoods, this study suggests that the maintenance of all animal species and guilds might be best achieved through the management of a heterogeneous landscape at a large spatial scale that separates anthropogenic disturbances from one another. The landscape could include three different land use areas: high biodiversity protected areas, production forests, and community use zones where strict biodiversity conservation, logging, and hunting each have a place. This management strategy could help avoid changes in species abundances that come with combined disturbances. The next challenge for conservation research is to determine how to manage the landscape. What level of hunting maintains tropical game populations? What intensity of timber extraction sustains an animal community that 
can provide the ecological services necessary for forest regeneration and regrowth? What size of protected area is necessary to facilitate recovery of adjacent degraded forest? The existence of verdant tropical forests mostly untouched by humans might be a thing of the past, but through informed management we might still be able to maintain most of the biodiversity and ecosystem functions of the forests.

\section{ACKNOWLedgments}

We thank the Government of Congo and its Ministries of Forestry Economy and Scientific Research for their support. The Wildlife Conservation Society provided logistical support, and we owe thanks to its staff, particularly P. Elkan, S. Elkan, B. Curran, M. Gately, E. Stokes, C. Prevost, J. Beck, and J. Mokoko. We also acknowledge the Buffer Zone Project (PROGEPP) and the Congolaise Industrielle des Bois for their collaboration. The U.S. Fish and Wildlife Service Great Ape Fund generously provided financial support for this research. J. R. Poulsen and C. J. Clark were supported by a University of Florida Presidential fellowship (J. R. Poulsen), a School of Natural Resources and Environment alumni fellowship (C. J. Clark), and Environmental Protection Agency Science to Achieve Results (STAR) fellowships (91630801-0 [J. R. Poulsen] and 91643301-0 [C. J. Clark]). We thank O. Mbani, Y. Nganga, M. Mokoke, and I. Loungouba for their tireless fieldwork. T. Martin and P. Kuhnert generously gave advice on implementation of the ZIP models, and G. Fiske produced the study area map. Two anonymous reviewers provided helpful comments on the manuscript.

\section{Literature Cited}

Asner, G. P., M. Keller, R. Pereira, J. C. Zweede, and J. N. M. Silva. 2004. Canopy damage and recovery after selective logging in Amazonia: field and satellite studies. Ecological Applications 14(Supplement):S280-S298.

Barnes, R., K. Barnes, M. Alers, and A. Blom. 1991. Man determines the distribution of elephants in the rain forests of northern Gabon. African Journal of Ecology 29:177-187.

Blake, S., et al. 2007. Forest elephant crisis in the Congo Basin. PLoS Biology 5:1-9.

Bolker, B. M., M. Brooks, C. J. Clark, S. W. Geange, J. R. Poulsen, M. H. H. Stevens, and J. S. S. White. 2009 Generalized linear mixed models: a practical guide for ecology and evolution. Trends in Ecology and Evolution 24:127-135.

Broadbent, E. N., G. P. Asner, M. Keller, D. E. Knapp, P. J. C. Oliveira, and J. N. Silva. 2008. Forest fragmentation and edge effects from deforestation and selective logging in the Brazilian Amazon. Biological Conservation 141:1745-1757.

Brook, B. W., C. J. A. Bradshaw, L. P. Koh, and N. S. Sodhi. 2006. Momentum drives the crash: mass extinction in the tropics. Biotropica 38:302-305.

Brook, B. W., N. S. Sodhi, and P. K. L. Ng. 2003. Catastrophic extinctions follow deforestation in Singapore. Nature 424:420-423.

Buckland, S. T., D. R. Anderson, K. P. Burnham, J. L. Laake, D. L. Borchers, and L. Thomas. 2001. Introduction to distance sampling: estimating abundance of biological populations. Oxford University Press, Oxford, UK.

Cannon, C. H., D. R. Peart, and M. Leighton. 1998. Tree species diversity in commercially logged Bornean rainforest. Science 281:1366-1368.

Choler, P. 2005. Consistent shifts in Alpine plant traits along a mesotopographical gradient. Arctic, Antarctic, and Alpine Research 37:444-453.

Clark, C. J., J. R. Poulsen, B. M. Bolker, E. F. Connor, and V. T. Parker. 2005. Comparative seed shadows of bird-, monkey-, and wind-dispersed trees. Ecology 86:2684-2694.
Clark, C. J., J. R. Poulsen, R. Malonga, and P. W. Elkan. 2009. Logging concessions can extend the conservation estate for Central African tropical forests. Conservation Biology 23:1281-1293.

Clark, C. J., J. R. Poulsen, and V. T. Parker. 2001. The role of arboreal seed dispersal groups on the seed rain of a lowland tropical forest. Biotropica 33:606-620.

Cleary, D. F. R., T. J. B. Boyle, T. Setyawati, C. D. Anggraeni, E. E. Van Loon, and S. B. J. Menken. 2007. Bird species and traits associated with logged and unlogged forest in Borneo. Ecological Applications 17:1184-1197.

Congolaise Industrielle des Bois. 2006. Plan d'amenagement de l'unité forestière d'aménagement de Kabo (2005-2034). Ministry of Forest Economy, Brazzaville, Republic of the Congo.

Cottenie, K., and L. De Meester. 2003. Comment to Oksanen (2001): reconciling Oksanen (2001) and Hurlbert (1984). Oikos 100:394-396.

Crome, F. H. J., M. R. Thomas, and L. A. Moore. 1996. A novel Bayesian approach to assessing impacts of rain forest logging. Ecological Applications 6:1104-1123.

Curran, L. M., S. N. Trigg, A. K. McDonald, D. Astiani, Y. M. Hardiono, P. Siregar, I. Caniago, and E. Kasischke. 2004. Lowland forest loss in protected areas of Indonesian Borneo. Science 303:1000-1003.

Dirzo, R., E. Mendoza, and P. Ortiz. 2007. Size-related differential seed predation in a heavily defaunated neotropical rain forest. Biotropica 39:355-362.

Dirzo, R., and P. H. Raven. 2003. Global state of biodiversity and loss. Annual Review of Environment and Resources 28:137-167.

Doledec, S., D. Chessel, C. J. F. terBraak, and S. Champely. 1996. Matching species traits to environmental variables: a new three-table ordination method. Environmental and Ecological Statistics 3:143-166.

Dray, S., A. B. Dufour, and D. Chessel. 2007. The ade4 package-II: two-table and K-table methods. R News 7:47-52.

Dray, S., N. Pettorelli, and D. Chessel. 2002. Matching data sets from two different spatial samples. Journal of Vegetation Science 13:867-874.

Dunn, R. 2004. Recovery of faunal communities during tropical forest regeneration. Conservation Biology 18:302309.

Durrieu de Madron, L., B. Fontez, and B. Dipapounji. 2000. Dégâts d'exploitation et de débardage en fonction de l'intensité d'exploitation en forêt dense humide d'Afrique Centrale. Bois et Forêts des Tropiques 264:57-60.

Elkan, P. W., S. W. Elkan, A. Moukassa, R. Malonga, M. Ngangaoué, and J. L. D. Smith. 2006. Managing threats from bushmeat hunting in a timber concession in the Republic of Congo. Pages 395-415 in J. G. Robinson and E. L. Bennett, editors. Emerging threats to tropical forests. University of Chicago Press, Chicago, Illinois, USA.

Fa, J. E., S. F. Ryan, and D. J. Bell. 2005. Hunting vulnerability, ecological characteristics and harvest rates of bushmeat species in afrotropical forests. Biological Conservation 121:167-176.

Frazer, G. W., R. A. Fournier, J. A. Trofymow, and R. J. Hall. 2001. A comparison of digital and film fisheye photography for analysis of forest canopy structure and gap light transmission. Agricultural and Forest Meteorology 109:249-263.

Gardner, T. A., J. Barlow, L. W. Parry, and C. A. Peres. 2007. Predicting the uncertain future of tropical forest species in a data vacuum. Biotropica 39:25-30.

Gautier-Hion, A., et al. 1985. Fruit characters as a basis of fruit choice and seed dispersal in a tropical forest vertebrate community. Oecologia 65:324-337.

Gelman, A., and J. Hill. 2007. Data analysis using regression and multilevel/hierarchical models. Cambridge University Press, Cambridge, UK. 
Harris, D. J., and A. H. Wortley. 2008. Sangha trees: an illustrated identification manual. Royal Botanical Gardens, Edinburgh, Scotland.

Hausner, V. H., N. G. Yoccoz, and R. A. Ims. 2003. Selecting indicator traits for monitoring land use impacts: birds in northern coastal birch forests. Ecological Applications 13:999-1012.

Hedges, S., and D. Lawson. 2006. Dung survey standards for the MIKE programme. Convention on International Trade in Endangered Species of Wild Fauna and Flora (CITES) Monitoring the Illegal Killing of Elephants (MIKE) Programme, Nairobi, Kenya. 〈www.cites.org/eng/prog/MIKE/ index.shtml $\rangle$

Hockings, K. J., J. R. Anderson, and T. Matsuzawa. 2006. Road crossings in chimpanzees: a risky business. Current Biology 16:668-670.

Hurlbert, S. H. 1984. Pseudoreplication and the design of ecological field experiments. Ecological Monographs 54:187211.

Jerozolimski, A., and C. A. Peres. 2003. Bringing home the biggest bacon: a cross-site analysis of the structure of hunterkill profiles in Neotropical forests. Biological Conservation 111:415-425.

Kingdon, J. 1997. The Kingdon field guide to African mammals. Academic Press, London, UK.

Kuhnert, P. M., T. G. Martin, K. Mengersen, and H. P. Possingham. 2005. Assessing the impacts of grazing levels on bird density in woodland habitat: a Bayesian approach using expert opinion. Environmetrics 16:717-747.

Laing, S. E., S. T. Buckland, R. W. Burn, D. Lambie, and A. Amphlett. 2003. Dung and nest surveys: estimating decay rates. Journal of Applied Ecology 40:1102-1111.

Lamb, D., P. D. Erskine, and J. A. Parrotta. 2005. Restoration of degraded tropical forest landscapes. Science 310:16281632.

Lambert, D. 1992. Zero-inflated Poisson regression, with an application to defects in manufacturing. Technometrics 34:114.

Laporte, N. T., J. A. Stabach, R. Grosch, T. S. Lin, and S. J. Goetz. 2007. Expansion of industrial logging in Central Africa. Science 316:1451.

Laurance, W. F. 2001. The future of the Brazilian Amazon. Science 291:988.

Laurance, W. F. 2007. Have we overstated the tropical biodiversity crisis? Trends in Ecology and Evolution 22:6570.

Laurance, W. F., B. M. Croes, L. Tchignoumba, S. A. Lahm, A. Alonso, M. E. Lee, P. Campbell, and C. Ondzeano. 2006. Impacts of roads and hunting on central African rainforest mammals. Conservation Biology 20:1251-1261.

Lesica, P., and S. V. Cooper. 1999. Succession and disturbance in sandhills vegetation: constructing models for managing biological diversity. Conservation Biology 13:293-302.

MacKenzie, D. I., J. D. Nichols, G. B. Lachman, S. Droege, J. A. Royle, and C. A. Langtimm. 2002. Estimating site occupancy rates when detection probabilities are less than one. Ecology 83:2248-2255.

Martin, T. G., P. M. Kuhnert, K. Mengersen, and H. P. Possingham. 2005a. The power of expert opinion in ecological models using Bayesian methods: impact of grazing on birds. Ecological Applications 15:266-280.

Martin, T. G., B. A. Wintle, J. R. Rhodes, P. M. Kuhnert, S. A. Field, S. J. Low-Choy, A. J. Tyre, and H. P. Possingham. 2005b. Zero tolerance ecology: improving ecological inference by modelling the source of zero observations. Ecology Letters 8:1235-1246.

Mockrin, M. H. 2008. The spatial structure and sustainability of subsistence wildlife harvesting in Kabo, Congo. Dissertation. Columbia University, New York, New York, USA.

Morgan, D., and C. Sanz. 2006. Chimpanzee feeding ecology and comparisons with sympatric gorillas in the Goualougo
Triangle, Republic of Congo. Pages 97-122 in G. Hohmann, M. Robbins, and C. Boesch, editors. Primate feeding ecology in apes and other primates: ecological, physiological, and behavioural aspects. Cambridge University Press, Cambridge, UK.

Naughton-Treves, L., and W. Weber. 2001. Human dimensions of the African rain forest. Pages 22-46 in W. Weber, L. J. T. White, A. Vedder, and N. Naughton-Treves, editors. African rain forest ecology and conservation. Yale University Press, New Haven, Connecticut, USA.

Oksanen, L. 2001. Logic of experiments in ecology: Is pseudoreplication a pseudoissue? Oikos 94:27-38.

Plummer, M., N. G. Best, N. K. Cowles, and S. K. Vines. 2005. coda: output analysis and diagnostics for MCMC. R package, version 0.9-5. R Foundation for Statistical Computing, Vienna, Austria.

Poulsen, J. R., C. J. Clark, E. F. Connor, and T. B. Smith. 2002. Differential resource use by primates and hornbills: implications for seed dispersal. Ecology 83:228-240.

Poulsen, J. R., C. J. Clark, and G. Mavah. 2007. Wildlife management in a logging concession in Northern Congo: Can livelihoods be maintained through sustainable hunting? Pages $140-157$ in G. Davies and D. Brown, editors. Bushmeat and livelihoods. Blackwell, Oxford, UK.

Poulsen, J. R., C. J. Clark, G. Mavah, and P. W. Elkan. 2009. Bushmeat supply and consumption in a tropical logging concession in northern Congo. Conservation Biology 23:1597-1608.

Poulsen, J. R., C. J. Clark, and T. B. Smith. 2001. Seed dispersal by a diurnal primate community in the Dja Reserve, Cameroon. Journal of Tropical Ecology 17:787-808.

Putz, F. E., G. M. Blate, K. H. Redford, R. Fimbel, and J. Robinson. 2001. Tropical forest management and conservation of biodiversity: an overview. Conservation Biology 15:720.

R Development Core Team. 2008. R: a language and environment for statistical computing. Version 2.7.1. R Foundation for Statistical Computing, Vienna, Austria.

Rabanal, L. I., H. S. Kuehl, R. Mundry, M. M. Robbins, and C. Boesch. 2010. Oil prospecting and its impact on large rainforest mammals in Louango National Park. Biological Conservation 143:1017-1024.

Ribera, I., S. Doledec, I. S. Downie, and G. N. Foster. 2001. Effect of land disturbance and stress on species traits of ground beetle assemblages. Ecology 82:1112-1129.

Robinson, J. G., K. H. Redford, and E. L. Bennett. 1999. Conservation: wildlife harvest in logged tropical forests. Science 284:595-596.

Rode, K. D., C. A. Chapman, L. R. McDowell, and C. Stickler. 2006. Nutritional correlates of population density across habitats and logging intensities in redtail monkeys (Cercopithecus ascanius). Biotropica 38:625-634.

Soares, B. S., D. C. Nepstad, L. M. Curran, G. C. Cerqueira, R. A. Garcia, C. A. Ramos, E. Voll, A. McDonald, P. Lefebvre, and P. Schlesinger. 2006. Modelling conservation in the Amazon basin. Nature 440:520-523.

Sodhi, N. S., L. P. Koh, B. W. Brook, and P. K. L. Ng. 2004. Southeast Asian biodiversity: an impending disaster. Trends in Ecology and Evolution 19:654-660.

Spiegelhalter, D. J., A. Thomas, N. G. Best, and D. Lunn. 2003. WinBUGS. Version 1.4. Imperial College and MRC Biostatistics Unit, Oxford, UK.

Stokes, E. J., et al. 2010. Monitoring great ape and elephant abundance at large spatial scales: measuring effectiveness of a conservation landscape. PLoS ONE 5:e10294.

Tenenhaus, M., and F. W. Young. 1985. An analysis and synthesis of multiple correspondence analysis, optimal scaling, dual scaling, homogeneity analysis and other methods for quantifying categorical multivariate data. Psychometrika 50:91-119. 
Terborgh, J., G. Nunez-Iturri, N. C. A. Pitman, F. H. C. Valverde, P. Alvarez, V. Swamy, E. G. Pringle, and C. E. T. Paine. 2008. Tree recruitment in an empty forest. Ecology 89:1757-1768.

Thomas, L., et al. 2006. Distance 5.0. Research Unit for Wildlife Population Assessment, University of St. Andrews, St. Andrews, UK.

Tutin, C. E. G., R. M. Ham, L. J. T. White, and M. J. S. Harrison. 1997. The primate community of the Lopé Reserve, Gabon: diets, responses to fruit scarcity, and effects on biomass. American Journal of Primatology 42:1-24.

Tyre, A. J., B. Tenhumberg, S. A. Field, D. Niejalke, K. Parris, and H. P. Possingham. 2003. Improving precision and reducing bias in biological surveys: estimating false-negative error rates. Ecological Applications 13:1790-1801.

Van Gemerden, B. S., G. N. Shu, and H. Olff. 2003. Recovery of conservation values in Central African rain forest after logging and shifting cultivation. Biodiversity and Conservation 12:1553-1570.

Walsh, P. D., and L. J. T. White. 2005. Evaluating the steady state assumption: simulations of gorilla nest decay. Ecological Applications 15:1342-1350.

White, L. J. T., C. E. G. Tutin, and M. Fernandez. 1993. Group composition and diet of forest elephants, Loxodonta africana cyclotis matschie 1900, in the Lopé Reserve, Gabon. African Journal of Ecology 31:181-199.

Whitney, K. D., M. K. Fogiel, A. M. Lamperti, K. M. Holbrook, D. J. Stauffer, B. D. Hardesty, V. T. Parker, and
T. B. Smith. 1998. Seed dispersal by Ceratogymna hornbills in the Dja Reserve, Cameroon. Journal of Tropical Ecology 14:351-371.

Wilkie, D., E. Shaw, F. Rotberg, G. Morelli, and P. Auzel. 2000. Roads, development, and conservation in the Congo basin. Conservation Biology 14:1614-1622.

Wright, S. J. 2003. The myriad consequences of hunting for vertebrates and plants in tropical forests. Perspectives in Plant Ecology, Evolution and Systematics 6:73-86.

Wright, S. J., A. Hernandez, and R. Condit. 2007a. The bushmeat harvest alters seedling banks by favoring lianas, large seeds, and seeds dispersed by bats, birds, and wind. Biotropica 39:363-371.

Wright, S. J., and H. C. Muller-Landau. 2006a. The future of tropical forest species. Biotropica 38:287-301.

Wright, S. J., and H. C. Muller-Landau. 2006b. The uncertain future of tropical forest species. Biotropica 38:443-445.

Wright, S. J., K. E. Stoner, N. Beckman, R. T. Corlett, R. Dirzo, H. C. Muller-Landau, G. Nunez-Iturri, C. A. Peres, and B. C. Wang. 2007b. The plight of large animals in tropical forests and the consequences for plant regeneration. Biotropica 39:289-291.

Wright, S. J., H. Zeballos, I. Dominguez, M. M. Gallardo, M. C. Moreno, and R. Ibanez. 2000. Poachers alter mammal abundance, seed dispersal, and seed predation in a neotropical forest. Conservation Biology 14:227-239.

\section{SUPPLEMENT 1}

Parameter values and statistics for the full zero-inflated Poisson (ZIP) model, including latitude and longitude, for eight animal guilds (Ecological Archives A021-082-S1).

\section{SUPPLEMENT 2}

Parameter values and statistics for the disturbance ZIP models (excluding latitude and longitude) for eight animal guilds (Ecological Archives A021-082-S2).

\section{SUPPLEMENT 3}

WinBUGS code for fitting a ZIP mixture model to estimate densities of animal guilds (Ecological Archives A021-082-S3). 